\title{
Morbidity and mortality of nonagenarians undergoing CoreValve implantation
}

\author{
Ibrahim Akin ${ }^{1 *}$, Stephan Kische ${ }^{1}$, Lylia Paranskaya ${ }^{1}$, Henrik Schneider ${ }^{1}$, Tim C Rehders ${ }^{1}$, Gökmen R Turan ${ }^{1}$, \\ Dimitar Divchev', Gunther Kundt², Ilkay Bozdag-Turan' ${ }^{1}$, Jasmin Ortak ${ }^{1}$, Ralf Birkemeyer ${ }^{1}$, Christoph A Nienaber ${ }^{1}$ \\ and Hüseyin Ince ${ }^{1}$
}

\begin{abstract}
Background: Nonagenarians are mostly denied from different therapeutic strategies due to high comorbidity index and risk-benefit calculation. We present the results of nonagenarians with high comorbidity index not eligible for conventional aortic valve surgery undergoing transcatheter aortic valve implantation (TAVI) with the CoreValve system.

Methods: Our retrospective analysis include baseline parameters, procedural characteristics, morbidity, mortality as well as twelve-lead surface ECG and echocardiographic parameters which were revealed preinterventionally, at hospital discharge and at 30-day follow-up. Clinical follow-up was performed 6 months after TAVI.

Results: Out of 158 patients 11 nonagenarians with a mean age of $92.6 \pm 1.3$ years suffering from severe aortic valve stenosis and elevated comorbidity index (logistic EuroSCORE of $32.0 \pm 9.5 \%$, STS score $25.3 \pm 9.7 \%$ ) underwent TAVI between January 2008 and January 2011 using the third-generation percutaneous self-expanding CoreValve prosthesis. Baseline transthoracic echocardiography reported a mean aortic valve area (AVA) of $0.6 \pm 0.2 \mathrm{~cm}^{2}$ with a mean and peak pressure gradient of $60.2 \pm 13.1 \mathrm{mmHg}$ and $91.0 \pm 27.4 \mathrm{mmHg}$, respectively. The 30-day follow up all cause and cardiovascular mortality was $27.3 \%$ and $9.1 \%$, respectively. One major stroke (9.1\%), 2 pulmonary embolisms (18.2\%), 1 periprocedural (9.1\%) and 1 (9.1\%) spontaneous myocardial infarction occured. Life-threatening or disabling bleeding occurred in 2 cases (18.2\%), and minor bleeding in 7 cases (63.6\%). Mean severity of heart failure according to NYHA functional class improved from $3.2 \pm 0.8$ to $1.36 \pm 0.5$ while mean AVA increased from $0.6 \pm 0.2 \mathrm{~cm}^{2}$ to $1.8 \pm 0.2 \mathrm{~cm}^{2}$. At 6-months follow-up 8 patients (72.7\%) were alive without any additional myocardial infarction, pulmonary embolism, bleeding, or stroke as compared to 30-day follow-up.
\end{abstract}

Conclusion: Our case series demonstrate that even with elevated comorbidity index, clinical endpoints and valve-associated results are relatively favorable in nonagenarians treated with CoreValve.

Keywords: CoreValve, Aortic stenosis, Nonagenarian, Surgery, TAVI

\section{Background}

Aortic valve stenosis (AS) is the most common native valve disease, becoming more prevalent with the ageing population [1]. The only definitive therapy for patients with severe symptomatic AS consists of surgical valve replacement [1]. However, conventional valve surgery is associated with high mortality and morbidity for some patients due to high comorbidity index.

\footnotetext{
* Correspondence: Ibrahim.akin@med.uni-rostock.de

${ }^{1}$ Heart Center Rostock, Department of Internal Medicine I, University Hospital Rostock, Rostock School of Medicine, Ernst-Heydemann-Str. 6, 18057, Rostock, Germany

Full list of author information is available at the end of the article
}

This leads to conservative management of these patients despite the poor prognosis associated with medical therapy [2]. Since its introduction in 2002 [3], TAVI proves to be a robust technique in the treatment of severe symptomatic AS in high surgical risk patients [4-7]. This study firstly evaluated the outcomes of TAVI in nonagenarians presenting a comorbidity index too high for conventional surgical valve replacement.

\section{Methods}

\section{Patients}

In our retrospective analysis, between January 2008 and January 2011, 11 nonagenarians out of a total amount

\section{Ciomed Central}


of 158 patients who underwent TAVI using the thirdgeneration percutaneous self-expanding CoreValve prosthesis (Medtronic, Minneapolis, MN, USA) were identified for this case series. The criteria for inclusion and exclusion to the TAVI procedure have been described elsewhere [4-7]. In brief, patients were included with echocardiographic measurements demonstrating severe native valvular AS with an area $<1 \mathrm{~cm}^{2}$, or $<0.6 \mathrm{~cm}^{2} / \mathrm{m}^{2}$ regardless of adjunct regurgitation; a diameter of the basal orifice of the stenosed valve between $20 \mathrm{~mm}$ and $27 \mathrm{~mm}$; and a diameter at the sinutubular junction $\leq 43 \mathrm{~mm}$. Most importantly, all patients were considered unfit for open surgery with an EuroSCORE $\geq 20 \%[4,8]$. TAVI was suggested in agreement between a cardiac surgeon and both, a clinical and interventional cardiologist; patient's or referring physician's preference was not relevant. Treatment strategy was in compliance with the Helsinki Declaration. Our local ethics committee approved this treatment strategy. Patients gave informed consent prior TAVI. Pacemaker implantation at follow-up was considered indicated in case of complete AV block and type II second-degree AV block.

\section{Procedure}

Details of the implantation procedures have been described elsewhere [4-7]. In brief, all patients were operated in a hybride interventional suite under general anaesthesia to assure stable hemodynamics and minimize patient movement during valve implantation. TAVI was performed via femoral access under fluoroscopic imaging by using the ProStar XL system (Abbott Vascular, Illinois, USA). The aortic valve was initially dilated using a standard valvuloplasty balloon $(18-25 \mathrm{~mm} \times 40-100 \mathrm{~mm})$ with a nominal diameter slightly $(2-6 \mathrm{~mm})$ smaller than the aortic valve and followed by CoreValve insertion [4-7] and in case of residual aortic insufficiency a post-TAVI balloon dilatation to ensure complete apposition. After procedure patients were transferred to intensive care unit (ICU). To assess conduction disorders, ECG monitoring was continuously performed over 7 days. All patients were prophylactically given a temporary pacemaker via femoral venous access; with VVI mode the active pacing was $40 \mathrm{bpm}$.

\section{Definitions}

Definitions of all clinical outcomes were performed according to the Valve Academic Research Consortium [9].

\section{Statisitical methods}

All data were processed using the SPSS statistical package for windows, release 16.0 (Chicago, Illinois, USA). The descriptive statistical characteristics for quantitative parameters are listed for normally distributed data in mean \pm standard deviation and in non-normally distributed data in median with interquartile range.

\section{Results}

Out of 158 patients a total of 11 nonagenarians with a mean age of $92.6 \pm 1.3$ years underwent TAVI at our institution from January 2008 to January 2011. Clinical presentation was dominated by dyspnoe (100\%), angina (36.4\%), syncope (36.4\%) and acute heart failure (45.5\%). The mean New York Heart Association (NYHA) functional class was 3.2 \pm 0.8 . Many patients suffered from high comorbidity index resulting in a mean logistic EuroSCORE of $32.0 \pm 9.5 \%$ and a STS score of $25.3 \pm 9.7 \%$ (Table 1). Baseline transthoracic echocardiography reported a mean AVA of $0.6 \pm 0.2 \mathrm{~cm}^{2}$ with a mean and peak pressure gradient of $60.2 \pm 13.1 \mathrm{mmHg}$ and $91.0 \pm 27.4 \mathrm{mmHg}$, respectively. Out of 11 patients $9(81.8 \%)$ had mild and $1(9.1 \%)$ had moderate aortic regurgitation, respectively. The analysis of ECGs revealed sinus rhythm in 8 patients (72.7\%) and atrial fibrillation in 1 individual (9.1\%) (Table 2).

TAVI was successfully performed in all patients (100\%) and no conversion to surgical AVR was necessary. In 2 cases we had an embolization of the valve. In both cases the valves were not completely released and thus were re-captured and implanted in a proper position. Mean procedure and fluoroscopy time was $110.3 \pm 29.5 \mathrm{~min}$ and $16.0 \pm 6.8 \mathrm{~min}$, respectively. Mean ICU stay was $3.36 \pm 1.9$ days, whereas mean hospital stay was $18.5 \pm 5.4$ days (Table 3 ).

All cause and cardiovascular mortality was $18.2 \%(\mathrm{n}=2)$ and $9.1 \%(n=1)$, respectively. One major stroke $(9.1 \%)$, 1 minor stroke (9.1\%) and 2 TIAs (18.2\%) occurred. One patient each $(9.1 \%)$ experienced a periprocedural (<72h) myocardial infarction and a spontaneous myocardial infarction, whereas 1 patient $(9.1 \%)$ was in need for new hemodialysis. Life threatening or disabling bleeding occurred in 2 cases (18.2\%), and minor bleeding in 7 cases $(63.6 \%)$. Three patients were in need for pacing (27.3\%) (Table 4).

30-day follow up all cause and cardiovascular mortality was $27.3 \%(\mathrm{n}=3)$ and $9.1 \%(\mathrm{n}=1)$, respectively. One major stroke (9.1\%), 2 minor strokes (18.2\%) and 3 TIAs (27.3\%) occurred. There were 1 periprocedural $(<72 \mathrm{~h})$ myocardial infarction (9.1\%), and 1 spontaneous myocardial infarctions $(9.1 \%)$ requiring percutaneous coronary intervention (PCI) at a mean follow-up of 13 days. Ten patients $(90.9 \%)$ presented combined safety endpoints. Mean severity of heart failure according to the NYHA functional class was $1.36 \pm 0.5$. Transthoracic echocardiography revealed a mean AVA and aortic mean pressure gradient of $1.8 \pm 0.2 \mathrm{~cm}^{2}$ and $8.3 \pm 3.9 \mathrm{mmHg}$, respectively (Table 5).

At 6 months follow-up 8 patients (72.7\%) were alive without any additional myocardial infarction, pulmonary embolism, bleeding, TIA or stroke. Mean severity of NYHA functional class was $1.34 \pm 0.7$. 
Table 1 Baseline characteristics of the study population $(n=11)$

\begin{tabular}{|c|c|}
\hline Variable & \\
\hline \multicolumn{2}{|l|}{ Clinical parameters } \\
\hline Male, n (\%) & $4(36.4)$ \\
\hline Age (yrs) & $92.6 \pm 1.3$ \\
\hline BMI $\left(\mathrm{kg} / \mathrm{m}^{2}\right)$ & $28.6 \pm 3.0$ \\
\hline Hypertension, n (\%) & $9(81.8)$ \\
\hline Dyslipidemia (\%) & $9(81.8)$ \\
\hline Smoker, n (\%) & $3(27.3)$ \\
\hline Diabetes mellitus, n (\%) & $7(63.6)$ \\
\hline Renal insufficiency (creatinine level > 1.5mg/dl), n (\%) & $6(54.5)$ \\
\hline Chronic hemodyalisis, n (\%) & $2(18.2)$ \\
\hline Chronic obstructive pulmonary disease, $\mathrm{n}(\%)$ & $2(18.2)$ \\
\hline New York Heart Association functional class (grade) & $3.2 \pm 0.8$ \\
\hline Logistic EuroSCORE (\%) & $32.0 \pm 9.5$ \\
\hline STS score (\%) & $25.3 \pm 9.7$ \\
\hline Dyspnoe, n (\%) & $11(100)$ \\
\hline Angina, n (\%) & $4(36.4)$ \\
\hline Syncope, n (\%) & $4(36.4)$ \\
\hline Cardiac decompensation, $\mathrm{n}(\%)$ & $5(45.5)$ \\
\hline Pulmonal artery systolic pressure $(\mathrm{mmHg})$ & $40.8 \pm 18.7$ \\
\hline Porcelain aorta, $\mathrm{n}(\%)$ & $0(0)$ \\
\hline Ischemic heart disease, n (\%) & $8(72.7)$ \\
\hline Previous percutaneous coronary intervention, n (\%) & $6(54.5)$ \\
\hline Previous coronary artery bypass graft surgery, n (\%) & $4(36.4)$ \\
\hline Peripheral vessel disease, $\mathrm{n}(\%)$ & $2(18.2)$ \\
\hline Previous stroke, n (\%) & $2(18.2)$ \\
\hline \multicolumn{2}{|l|}{ Laboratory findings } \\
\hline Hemoglobin (mg/dl) & $7.8 \pm 1.2$ \\
\hline Hematokrit (\%) & $37.7 \pm 4.8$ \\
\hline Creatinine $(\mu \mathrm{mol} / \mathrm{l})$ & $183.9 \pm 223.6$ \\
\hline MDRD & $48.2 \pm 24.6$ \\
\hline \multicolumn{2}{|l|}{ Medication } \\
\hline Aspirin & $7(63.6)$ \\
\hline ACE-Inhibitor & $7(63.6)$ \\
\hline ARB & $2(18.2)$ \\
\hline Beta-Blocking agent & $8(72.7)$ \\
\hline Ca-chanel blocker & $3(27.3)$ \\
\hline Antiarythmic agent & $0(0)$ \\
\hline Statin & $7(63.6)$ \\
\hline
\end{tabular}

\section{Discussion}

With the ageing population the demand for cardiac operations in elderly patients has steadily increased over the last 10 to 15 years. Moderate-to-severe AS occurs in $5 \%$ of individuals 75 to 86 years of age, and critical AS is seen in $>5 \%$ of those $>85$ years of age [10]. In-hospital
Table 2 Echocardiographic and electrocardiographic parameters

\begin{tabular}{|c|c|}
\hline \multicolumn{2}{|c|}{ Echocardiographic parameters } \\
\hline Left ventricular ejection fraction (\%) & $44.6 \pm 7.8$ \\
\hline Aortic valve area $\left(\mathrm{cm}^{2}\right)$ & $0.6 \pm 0.2$ \\
\hline Peak pressure gradient $(\mathrm{mmHg})$ & $91.0 \pm 27.4$ \\
\hline Mean pressure gradient $(\mathrm{mmHg})$ & $60.2 \pm 13.1$ \\
\hline Aortic annulus dimension (mm) & $20.7 \pm 3.5$ \\
\hline Aortic bulbus dimension (mm) & $29.7 \pm 4.1$ \\
\hline Left ventriculae end-diastolic diemater ( $\mathrm{mm}$ ) & $54.6 \pm 7.7$ \\
\hline Interventricular septal dimension (mm) & $13.2 \pm 1.9$ \\
\hline Aortic regurgitation, $\mathrm{n}(\%)$ & 10 \\
\hline Grade I & $9(81.8)$ \\
\hline Grade II & $1(9.1)$ \\
\hline Grade III & 0 \\
\hline \multicolumn{2}{|l|}{ Mitral insufficiency, n (\%) } \\
\hline Grade I & $6(54.5)$ \\
\hline Grade II & $4(36.4)$ \\
\hline Grade III & 0 \\
\hline \multicolumn{2}{|c|}{ Electrocardiographic parameters } \\
\hline Sinus rhythm, n (\%) & $8(72.7)$ \\
\hline Atrial fibrillation, n (\%) & $1(9.1)$ \\
\hline Pacemaker, n (\%) & $2(18.2)$ \\
\hline Heart rate (bpm) & $70.1 \pm 10.7$ \\
\hline $\mathrm{PQ}$ interval (ms) & $199.4 \pm 62.8$ \\
\hline QRS width (ms) & $112.6 \pm 23.4$ \\
\hline QT interval (ms) & $397.5 \pm 30.7$ \\
\hline Left bundle branch block, n (\%) & $0(0)$ \\
\hline Right bundle branch block, n (\%) & $0(0)$ \\
\hline Left anterior hemiblock, n (\%) & $2(18.2)$ \\
\hline Left posterior hemiblock, n (\%) & $0(0)$ \\
\hline
\end{tabular}

death and stroke rates may be as high as $8.5 \%$ and $8 \%$, respectively [11]. Mean duration of postoperative hospital stay in most reports is $>2$ weeks for very elderly patients, with most being discharged to nursing care facilitates.

Today, about one third of patients with severe AS are not referred for valve replacement surgery because of the risk perceived by both patients and physicians. TAVI is a robust technique, which offers advantages to high surgical risk patients [5-7]. Elderly with AS often present comorbidities, which are responsible for the considerable heterogeneity of operative risk and which hamper the decision, if the beneficial outcome of surgery, compared with spontaneous outcome, outweighs the risk of intervention. However there are no explicit age related restrictions for surgical aortic valve replacement according to guidelines on treatment of severe symptomatic AS $[1,11]$. In nonagenarians, age alone accounts for a predicted logistic EuroSCORE mortality risk of $6.55 \%$ for male 
Table 3 Intraoperative data of patients

\begin{tabular}{lc}
\hline \multicolumn{1}{c}{ Parameter } & \\
\hline Procedural success, $\mathrm{n}(\%)$ & $11(100)$ \\
\hline Conversion to surgical AVR, $\mathrm{n}(\%)$ & $1(9.1)$ \\
\hline Intraprocedural circulatory depression, $\mathrm{n}(\%)$ & $1(9.1)$ \\
\hline Catecholamine therapy, $\mathrm{n}(\%)$ & $1(9.1)$ \\
\hline Resuscitation, $\mathrm{n}(\%)$ & $1(9.1)$ \\
\hline Defibrillation, $\mathrm{n}(\%)$ & $1(9.1)$ \\
\hline Vascular access site complication requiring surgery, $\mathrm{n}(\%)$ & $120.9 \pm 44.7$ \\
\hline Contrast agent (ml) & $110.3 \pm 29.5$ \\
\hline Procedure time (min) & $16.0 \pm 6.8$ \\
\hline Fluoroscopy time (min) & $9(81.8)$ \\
\hline CoreValve size (mm) & $2(18.2)$ \\
\hline 26 & $11(100)$ \\
\hline 29 & $5(45.5)$ \\
\hline Pre TAVI valvuloplasty, $\mathrm{n}(\%)$ & $1.2 \pm 0.6$ \\
\hline Post TAVI valvuloplasty, $\mathrm{n}(\%)$ & $20.6 \pm 1.8$ \\
\hline Number of inflations after TAVI (n) & $62.7 \pm 16.8$ \\
\hline Balloon diameter (mm) & $2(18.2)$ \\
\hline Balloon length (mm) & $5.3 \pm 4.1$ \\
\hline Valve embolization, $\mathrm{n}(\%)$ & $0.9 \pm 0.45$ \\
\hline Post TAVl aortic valve mean gradient & $3.36 \pm 1.9$ \\
\hline Angiographic aortic insufficiency (grade) & $18.5 \pm 5.4$ \\
\hline ICU stay (days) & \\
\hline Hospital stay (days) & \\
\hline &
\end{tabular}

patients, as for females it raises to $8.89 \%$ without any other preoperative risk factors [8]. In our series predicted logistic EuroSCORE mortality rate was $32.0 \pm 9.5 \%$ for whole cohort. Feasibility of TAVI on nonagenarians was proven by the high procedural success rate $(100 \%)$. The reduction in afterload after TAVI resulted in immediate marked hemodynamic improvement and translated into symptomatic relief, with a reduction in NYHA class by a mean of 1.8 grades. We also show markedly improvements in the AVA from 0.6 to $1.8 \mathrm{~cm}^{2}$ and reductions in mean pressure gradients from 60.2 to $8.3 \mathrm{mmHg}$, which compare favorably to the results for younger patients treated with TAVI $[5,6,12,13]$.

Safety was assessed using primary and secondary endpoints following recommendations of the Valve Academic Research Consortium [9]. As there is no trial exclusively in nonagenarians or subgroup analyses of large trials our outcomes are not comparable with the literature.

All-cause mortality is considered as the "gold standard" in surgical clinical trials with cardiovascular mortality as an important secondary endpoint $[4,9,14]$. In our study the 30-day follow up all cause and cardiovascular mortality was $27.3 \%$ and $9.1 \%$, respectively, which is slightly higher or comparable to $11.4 \%$ to $29 \%$ all cause mortality
Table 4 In-hospital outcome of patients

\begin{tabular}{|c|c|}
\hline In-hospital outcome & \\
\hline \multicolumn{2}{|l|}{ Mortality, n (\%) } \\
\hline All cause n (\%) & $2(18.2)$ \\
\hline Cardiovascular, n(\%) & $1(9.1)$ \\
\hline \multicolumn{2}{|l|}{ Stroke, n (\%) } \\
\hline Major & $1(9.1)$ \\
\hline Minor & $1(9.1)$ \\
\hline TIA, n (\%) & $2(18.2)$ \\
\hline \multicolumn{2}{|l|}{ Myocardial infarction, n (\%) } \\
\hline Periprocedural (<72h) & $1(9.1)$ \\
\hline Spontaneous (>72h) & $1(9.1)$ \\
\hline Pneumonia, n (\%) & $1(9.1)$ \\
\hline Sepsis, n (\%) & $1(9.1)$ \\
\hline Pulmonary embolism & $1(9.1)$ \\
\hline \multicolumn{2}{|l|}{ Acute kidney injury, n (\%) } \\
\hline Grade I & $3(27.3)$ \\
\hline Grade II & $0(0)$ \\
\hline Grade III & $1(9.1)$ \\
\hline New need for hemodialysis & $1(9.1)$ \\
\hline \multicolumn{2}{|l|}{ Bleeding, $\mathrm{n}(\%)$} \\
\hline Life-threatening or disabling & $2(18.2)$ \\
\hline Major & $0(0)$ \\
\hline Minor & $7(63.6)$ \\
\hline \multicolumn{2}{|l|}{ Vascular complication } \\
\hline Major & $1(9.1)$ \\
\hline Minor & $3(27.3)$ \\
\hline Need for Pacing, n (\%) & $3(27.3)$ \\
\hline New left bundle branch block & $6(54.6)$ \\
\hline New second or third-degree AV block & $3(27.3)$ \\
\hline Need for Re-do (TAVI or Surgery) & $0(0)$ \\
\hline
\end{tabular}

for nonagenarians with low comorbidity index as stated by the estimated logistic EuroSCORE treated with surgical aortic valve replacement [15-18] and 5\% to $20 \%$ all-cause and $10 \%$ cardiovascular mortality for TAVI performed at younger patients [5-7].

Like mortality, operative morbidity in the elderly is higher than in younger patients. This is true in particular for the frequency of stroke. Some authors have shown that older age is strongly related to a neurological event, the latter being associated with a previous history of stroke and advanced atherosclerotic disease [19]. We report one major stroke (9.1\%) in our cohort, which compares to $2.1 \%$ to $8.9 \%$ in a nonagenarian population treated with surgical aortic valve replacement [5-7] and $0 \%$ to $10 \%$ for TAVI performed at younger patients $[5-7,13]$. Our periprocedural $(<72 \mathrm{~h})(9.1 \%)$, and spontaneous $(9.1 \%)$ myocardial infarction rate is markedly higher compared to $0 \%$ to $0.3 \%$ for TAVI performed at 
Table 5 30-day follow-up of patients

\begin{tabular}{|c|c|}
\hline \multicolumn{2}{|l|}{ 30-day outcome } \\
\hline Mortality, n (\%) & \\
\hline All cause $n(\%)$ & $3(27.3)$ \\
\hline Cardiovascular, n(\%) & $1(9.1)$ \\
\hline \multicolumn{2}{|l|}{ Stroke, n (\%) } \\
\hline Major & $1(9.1)$ \\
\hline Minor & $2(18.2)$ \\
\hline TIA, n (\%) & $3(27.2)$ \\
\hline \multicolumn{2}{|l|}{ Myocardial infarction, n (\%) } \\
\hline Periprocedural (<72h) & $1(9.1)$ \\
\hline Spontaneous (>72h) & $1(9.1)$ \\
\hline New need for hemodialysis & $2(18.2)$ \\
\hline \multicolumn{2}{|l|}{ Bleeding, n (\%) } \\
\hline Life-threatening or disabling & $2(18.2)$ \\
\hline Major & $0(0)$ \\
\hline Minor & $7(63.6)$ \\
\hline \multicolumn{2}{|l|}{ Vascular complication } \\
\hline Major & $1(9.1)$ \\
\hline Minor & $3(27.3)$ \\
\hline Pulmonary embolism & $2(18.2)$ \\
\hline Combined safety endpoints & $10(90.9)$ \\
\hline Need for Pacing, n (\%) & $5(45.5)$ \\
\hline New left bundle branch block & $7(63.7)$ \\
\hline New second or third-degree AV block & $5(45.5)$ \\
\hline NYHA functional class & $1.36 \pm 0.5$ \\
\hline Cardiac decompensation, n (\%) & $2(18.2)$ \\
\hline Syncope, n (\%) & $0(0)$ \\
\hline Need for hospitalization due to cardiac causes, n (\%) & $3(27.2)$ \\
\hline Need for Re-do (TAVI or Surgery) & $0(0)$ \\
\hline
\end{tabular}

\begin{tabular}{lr}
\hline Left ventricular ejection fraction (\%) & $45.6 \pm 6.9$ \\
Left ventriclura end-diastolic diameter (mm) & $50.1 \pm 7.1$ \\
Aortic valve area $\left(\mathrm{cm}^{2}\right)$ & $1.8 \pm 0.2$ \\
Aortic peak pressure gradient (mmHg) & $16.6 \pm 6.7$ \\
Aortic mean pressure gradient (mmHg) & $8.3 \pm 3.9$ \\
Interventricular septal dimension (mm) & $13.5 \pm 1.6$ \\
Aortic regurgitation, $\mathrm{n}(\%)$ & \\
Grade I & $9(81.9)$ \\
Grade II & $2(18.2)$ \\
Grade III & $0(0)$ \\
Pulmonal artery systolic pressure & $45.7 \pm 14.6$ \\
Mitral insufficiency (\%) & $8(72.8)$ \\
Grade I & $2(18.2)$ \\
Grade II & $0(0)$ \\
Grade III
\end{tabular}

younger patients $[5-7,13]$ and $5.7 \%$ for surgical valve replacement performed at nonagenarians [16] pointing out the high cardiovascular risk profile of our severely ill patients. Two life-threatening or disabling bleeding occurred (18.2\%) which compares favorably to rates of $3.6 \%$ to $24 \%$ for TAVI performed at younger patients [5-7,13]. Vascular complications after TAVI occur with an incidence of $7.5 \%$ to $16.3 \%$ and remain a significant cause of mortality and morbidity [5-7,13]. We report similar rates of major and minor vascular complications. 3 patients presented acute kidney injury grade I (27.3\%), and one patient grad III (9.1\%), which is comparable to $6 \%$ to $28 \%$ of acute kidney injuries reported in the literature [20].

As shown in previous studies, the very elderly are more likely to experience postoperative complications, and consequently, a prolonged hospitalization and intensive therapy $[21,22]$. However, the length of hospital and ICU stay reported in our study $(18.5 \pm 5.4$ and $3.36 \pm 1.9$ days respectively) is comparable to data for younger patients ( 7 to 17 days and 2.8 days respectively [23].

In general population, life expectancy in nonagenarians is 2.5 and 3.5 years for men and women, respectively [24]. Although one should take into account the very advanced age and frailty of these subjects in the interpretation of such results, all-cause death is still not low despite successful TAVI. However, the patients who survived the follow-up achieved in most cases an improvement in their clinical symptoms. Thus, TAVI in the very elderly have the potential to significantly ameliorate functional status and quality of life, at the price of considerable periinterventional and follow-up mortality rates. The risk-benefit balance of TAVI of nonagenarians should then be considered to be paradigmatically different than in the younger candidates, in whom the prolongation of life is usually considered the primary aim. The clinician should consider these findings while evaluating the very elderly for TAVI and properly discuss these issues in the light of the patient's expectations.

\section{Conclusions}

Our case series demonstrate that even with elevated comorbidity index clinical endpoints and valve-associated results are relatively favorable in nonagenarians treated with CoreValve prosthesis. Due to the small sample size there is a need for more data from multicenter large-scale trials or registries to elucidate the role of TAVI in nonagenarian patients.

\section{Abbreviations}

AS: Aortic stenosis; AVA: Aortic valve area; AVR: Aortic valve replacement; ECG: Electrocardiography; ICU: Intensive care unit; NYHA: New York Heart Association; PCl: Percutaneous coronary intervention; TAVI: Transcatheter aortic valve implantation. 


\section{Competing interests}

The authors declare that they have no competing interests.

\section{Authors' contributions}

IA, SK, HI, HS, TCR, LP, DD, GRT, IBT, JO, RB, CAN participate in treating the patients during intervention/ICU and acquisition of data. IA, HI and CAN wrote the manuscript. IA and GK performed the statistical analyses. All authors read and approved the final manuscript.

\section{Author details}

${ }^{1}$ Heart Center Rostock, Department of Internal Medicine I, University Hospital Rostock, Rostock School of Medicine, Ernst-Heydemann-Str. 6, 18057, Rostock, Germany. ${ }^{2}$ Institute for Biostatistics and Information in Medicine and Ageing Research, Rostock School of Medicine, University Hospital Rostock, Ernst-Heydemann-Str 6, 18057, Rostock, Germany.

Received: 16 April 2012 Accepted: 20 September 2012 Published: 24 September 2012

\section{References}

1. Bonow RO, Carabello BA, Chatterjee K, de Leon AC Jr, Faxon DP, Freed MD, Gaasch WH, Lytle BW, Nishimura RA, O'Gara PT, O'Rourke RA, Otto CM, Shah PM, Shanewise JS, American College of Cardiology/American Heart Association Task Force on Practice Guidelines: 2008 focused update incorporated into the ACC/AHA 2006 guidelines for the management of patients with valvular heart disease: a report of the American College of Cardiology/American Heart Association Task Force on Practice Guidelines (Writing Committee to revise the 1998 guidelines for the management of patients with valvular heart disease). Endorsed by the Society of Cardiovascular Anesthesiologists, Society for Cardiovascular Angiography and Interventions, and Society of Thoracic Surgeons. J Am Coll Cardiol 2008, 52:e1-e142.

2. Varadarajan P, Kapoor N, Bansal RC, Pai RG: Clinical profile and natural history of 453 nonsurgically managed patients with severe aortic stenosis. Ann Thorac Surg 2006, 82:2111-2115.

3. Cribrier A, Eltchaninoff H, Bash A, Borenstein N, Tron C, Bauer F, Derumeaux $G$, Anselme F, Laborde F, Leon MB: Percutaneous transcatheter implantation of an aortic valve prosthesis for calcified aortic stenosis: first human case description. Circulation 2002, 106:3006-3008.

4. Vahanian A, Alfieri O, Al-Attar N, Antunes M, Bax J, Cormier B, Cribrier A, De Jaegere P, Fournial G, Kappetein AP, Kovac J, Ludgate S, Maisano F, Moat N, Mohr F, Nataf P, Pierard L, Pomar JL, Schofer J, Tornos P, Tuzcu M, van Hout $B$, von Segesser LK, Walther T, European Association of Cardio-Thoracic Surgery, European Association of Percutaneous Cardiovascular Interventions: Transcatheter valve implantation for patients with aortic stenosis: a position statement from the European Association of Cardio-Thoracic Surgery (EACTS) and the European Society of Cardiology (ESC), in collaboration with the European Association of Percutaneous Cardiovascular Intervention (EAPCI). Eur Heart J 2008, 29:1463-1470.

5. Grube E, Laborde JC, Gerckens U, Felderhoff T, Sauren B, Buellesfeld L, Mueller R, Menichelli M, Schmidt T, Zickmann B, Iversen S, Stone GW: Percutaneous implantation of the CoreValve self-expanding valve prosthesis in high-risk patients with aortic valve disease: the Siegburg first-in-man study. Circulation 2006, 114:1616-1624.

6. Webb JG, Chandavimol M, Thompson CR, Ricci DR, Carere RG, Munt BI Buller CE, Pasupati S, Lichtenstein S: Percutaneous aortic valve implantation retrograde from the femoral artery. Circulation 2006, 113:842-850.

7. Zahn R, Gerckens U, Grube E, Linke A, Sievert H, Eggebrecht H, Hambrecht R, Sack S, Hauptmann KE, Richardt G, Figulla HR, Senges J, German Transcatheter Aortic Valve Intervention-Regsitry Investigators: Transcatheter aortic valve implantation: first results from a multi-centre real-world registry. Eur Heart J 2011, 32:198-204

8. Roques F, Nashef SA, Michel P, Gauducheau E, de Vincentiis C, Baudet E, Cortina J, David M, Faichney A, Gabrielle F, Gams E, Harjula A, Jones MT, Pintor PP, Salamon R, Thulin L: Risk factors and outcome in European cardiac surgery: analysis of the EuroSCORE multinational database of 19030 patients. Eur J Cardiothorac Surg 1999, 15:816-822

9. Leon MB, Piazza N, Nikolsky E, Blackstone EH, Cutlip DE, Kappetein AP, Kucoff MW, Mack M, Mehran R, Miller C, Morel MA, Petersen J, Popma JJ, Takkenberg JJ, Vahanian A, van Es GA, Vranckx P, Webb JG, WIndecker S,
Serruys PW: Standardized endpoint definitions for transcatheter aortic valve implantation clinical trials: a consensus report from the Valve Academic Research Consortium. Eur Heart J 2011, 32:205-217.

10. Lindroos M, Kupari M, Heikkilä, Tilvis R: Prevalence of aortic valve abnormalities in the elderly: an echocardiographic study of a random population sample. J Am Coll Cardiol 1993, 21:1220-1225.

11. Kolh P, Kerzmann A, Lahaye L, Gerard P, Limet R: Cardiac surgery in octogenarians: peri-operative outcome and long-term results. Eur Heart J 2001, 22:1235-1243

12. Vahanian A, Baumgartner H, Bax J, Butchart E, Dion R, Filippatos $G$, Flachskamp F, Hall R, lung B, Kasprzak J, Nataf P, Tornos P, Torracca L, Wenink A, Task Force on the Management of Valvular Heart Disease of the European Society of Cardiology, ESC Committee for Practice Guidelines: Guidelines on the management of valvular heart disease. The Task Force on the management of valvular heart diseases of the European Society of Cardiology. Eur Heart J 2007, 28:230-268.

13. Eltchaninoff $H$, Prat $A$, Gillard $M$, Lequerrier $A$, Blanchard $D$, Fournial $G$, lung B, Donzeau-Gouge P, Tribouilloy C, Debrux JL, Pavie A, Gueret P, FRANCE Registry Investigators: Transcatheter aortic valve implantation: early results of the FRANCE (FRench Aortic National CoreValve and Edwards) registry. Eur Heart J 2011, 32:191-197.

14. Akins CW, Miller DC, Turina MI, Kouchoukos NT, Blackstone EH, Grunkemeier GL, Takkenberg JJ, David TE, Butcjardt EG, Adams DH, Shahian DM, Hagl S, Mayer JE, Lytle BW, Councils of the American Association for Thoracic Surgery, Society of Thoracic Surgeons; European Association for CardioThoracic Surgery; Ad Hoc Liaison Committee for Standardizing Definitions of Prosthetic Heart Valve Morbidity: Guidelines for reporting mortality and morbidity after cardiac valve interventions. J Thorac Cardiovasc Surg 2008, 135:732-738.

15. Bridges $C R$, Edwards FH, Peterson ED, Coombs LP, Ferguson TB: Cardiac surgery in nonagenarians and centenarians. J Am Coll Surg 2003, 197:347-356.

16. Edwards MB, Taylor KM: Outcomes in nonagenarians after heart valve replacement operation. Ann Thorac Surg 2003, 75:830-834.

17. Bacchetta MD, Ko W, Girardi LN, Mack CA, Krieger KH, Isom OW, Lee LY: Outcomes of cardiac surgery in nonagenarians: a 10-year experience. Ann Thorac Surg 2003, 75:1215-1220.

18. Roberts WC, Ko JM, Matter GJ: Aortic valve replacement for aortic stenosis in nonagenarians. Am J Cardiol 2006, 98:1251-1253.

19. Weintraub WS, Clements SD, Ware J, Craver JM, Cohen CL, Jones EL, Guyton RA: Coronary artery surgery in octogenarians. Am J Cardiol 1991, 68:1530-1534.

20. Aregger F, Wenaweser P, Hellige GJ, Kadner A, Carrel T, S WI, Frey FJ: Risk of acute kidney injury in patients with severe aortic valve stenosis undergoing transcatheter valve replacement. Nephrol Dial Transplant 2009, 24:2175-2179.

21. Dalrymple-Hay MJR, Alzetani A, Abdel-Nazar S, Haw M, Livesey S, Monro J: Cardiac surgery in the elderly. Eur J Cardiothoracic Surg 1999, 15:61-66.

22. Deiwick M, Tandler R, Möllhoff T, Kerber S, Rötker J, Roeder N, Scheld HH: Heart surgery in patients aged eighty years and above: determinants of morbidity and mortality. Thorac Cardiovasc Surg 1997, 45:119-126.

23. Yan TD, Cao C, Martens-Nielsen J, Pedang R, Nq M, Vallely MP, Bannon PG: Transcatheter aortic valve implantation for high-risk patients with severe aortic stenosis: A systematic review. J Thorac Cardiovasc Surg 2010, 139:1519-1528.

24. Levy Praschker BG, Leprince P, Bonnet N, Rama A, Bors V, Lievre L, Pavie A, Gandjbakhch I: Cardiac surgery in nonagenarians: hospital mortality and long-term follow-up. Interact Cardio Vasc Thorac Surg 2006, 5:696-699.

doi:10.1186/1471-2261-12-80

Cite this article as: Akin et al: Morbidity and mortality of nonagenarians undergoing CoreValve implantation. BMC Cardiovascular Disorders 2012 12:80. 